\title{
Evolutionary Game Analysis of Chinese Food Quality considering Effort Levels
}

\author{
Song Yang $\left(D,{ }^{1,2}\right.$ Jincai Zhuang, ${ }^{2}$ Aifeng Wang, ${ }^{3}$ and Yancai Zhang ${ }^{1}$ \\ ${ }^{1}$ College of Economics and Management, Huaiyin Normal University, Huai'an 23001, China \\ ${ }^{2}$ School of Management, Jiangsu University, Zhenjiang 212013, China \\ ${ }^{3}$ School of Mathematical Science, Huaiyin Normal University, Huai'an 23001, China \\ Correspondence should be addressed to Song Yang; yangsong8008@126.com
}

Received 14 June 2019; Revised 2 September 2019; Accepted 18 September 2019; Published 16 November 2019

Academic Editor: Michele Scarpiniti

Copyright (C) 2019 Song Yang et al. This is an open access article distributed under the Creative Commons Attribution License, which permits unrestricted use, distribution, and reproduction in any medium, provided the original work is properly cited.

Food safety accidents occur frequently, which has caused great harm to people's health. With the consideration that food quality requires the joint efforts of all members of the food supply chain and that quality-improving efforts for food have a positive external effect, we focus on the quality-improving effort level, which is very important for food quality and safety. This paper builds an evolutionary game model and employs the replicated dynamic equation to study evolutionarily stable strategies of suppliers and producers. Furthermore, simulation experiments are conducted to verify the modeling analyses and demonstrate the influences of game parameters. The research results show that the behavioral strategies are closely related to the factors such as the ratios of the input to the output, the cost of quality-improving efforts, the hitchhiking benefits, and the initial strategy. Only when the punishing dynamics of the government exceeds a certain value, both participants can choose the quality-improving effort strategy. Based on the results, this paper has provided some inspiration for policy-making of government institutions.

\section{Introduction}

In recent years, because of the frequent occurrence of food safety accidents, great damage has occurred to the health of the people, causing widespread concern in the society. The No. 1 document of China's central government in 2019 once again stressed the importance of improving the food quality, improving the standard system of food quality, and effectively ensuring the quality of food. The food supply chain usually involves the source's supply of raw materials, production and processing, retail, and so on. Risk factors in any link may lead to unsafe food. Therefore, the joint efforts of all the participant bodies in the food supply chain are required to ensure the food safety [1]. However, China currently faces many food quality challenges such as inferior infant formula, toxic capsules, diseased or dead pig, hormone-tainted fruits, lean meat powder, ditch oil, and abuse of food additives [2-5]. Many scholars believed that information asymmetry was one of the main causes for the issue of food safety [6,7]. Information asymmetry, on the one hand, leads to moral hazard; that is, food producers reduce their quality by making shoddy food and even produce fake and inferior food. On the other hand, it leads to adverse selection; that is, consumers choose low-quality products to avoid risks because they cannot effectively distinguish product quality [8,9]. The market failure caused by asymmetric information needs the participation of government regulation [10]. But a series of important food safety accidents have shaken the public confidence in the government's ability to manage food safety risks $[11,12]$. According to the public governance theory, the third party must be introduced to participate in governance in the case of "market failure" and "government failure". Therefore, cogovernance was proposed, the subjects of which include the government, nongovernmental organizations (social organizations and social media), market entities, and social individuals [13]. However, cogovernance is to coordinate the social, economic, and cultural environment and coordinate the interest conflicts of different groups [14]. If the conditions are not met, 
cogovernance is difficult to construct, the substance of which belongs to external governance. The fundamental solution to food safety problems is that all participants in the food supply chain make efforts to invest in quality. However, the quality effort input in the food supply chain has a positive external effect, which provides a strong incentive for the participants in the supply chain to hitchhike. Therefore, the government needs to take measures to encourage participants to take the initiative in quality input. In response to this, this paper studies the quality input behavior of food supply chain members from the perspective of quality effort.

The relationship between the effort behavior of members and the operation efficiency of the supply chain has always been a hot topic among scholars. He et al. [15] review the operation management research on food quality and safety and classify the related articles into four categories, that is, storage problems, distribution problems, marketing problems, and food traceability and safety problems. Roels et al. [16] discusses the impact of noncontractual arrangements on bilateral efforts and profits, and the results show that fixed-fee contracts are optimal when the service output is more sensitive to the vendor's effort, that time-and-materials contracts are optimal when the output is more sensitive to the buyer's effort, and that performance-based contracts are optimal when the output is sensitive to both the buyer's and the vendor's inputs. Kaya [17] finds that a linear contract, a quantity discount contract, and a simultaneous revenue and cost-sharing contract can coordinate the supply chain in the manufacturers' effort model. However, when the supplier is the one exerting the effort, only a simultaneous revenue and cost-sharing contract can coordinate the supply chain. Tsao and Sheen [18] consider a two-echelon multiple-retailer distribution channel with retailers' promotional efforts and the sales learning curve. The model shows that keeping the fraction of promotion cost sharing within an appropriate range increases profits for all parties. Taylor [19] shows that a properly designed target rebate and returns contract achieves coordination and a win-win outcome when demand is impacted by retailer sales effort. He et al. [20] explore a variety of contracts to coordinate the supply chain when the demand is influenced by both retail price and retailer sales effort. They find that only the properly designed returns policy with the SRP contract can achieve channel coordination and lead to Pareto improving the win-win situation for supply chain members.

Government regulation is the main way to solve food safety problems. Some scholars have studied the necessity of government regulation, and the results show that food safety is the basic responsibility of the government [21-23]. Other scholars have also discussed some problems in the China food regulatory system and proposed suggestions for the current situation. For example, Liu [24] thinks that China's food safety supervision has many problems, such as imperfect supervision system and mechanism, weak supervision capacity, decentralized supervision power allocation structure, and insufficient supervision independence. Ren et al. [25] explore the operational problems of traditional supervision, advocate to convert government functions, and change enterprises from "reactive" supervision to "autonomous" supervision. Cao et al. [26] suggest that the government should increase the inspection frequency of enterprises, reduce the cost of enterprise self-discipline, and increase the punishment of enterprises. Zhang [27] points out that government supervision should adopt scientific food safety supervision methods, and it has become an inevitable trend to use information means to realize fast and effective food safety management. The above studies emphasize that government regulation is very important in food safety. However, they neglect the impact of changes in the intensity of government regulation on food enterprises.

Because of the limitation of information, knowledge, environment, and so on, it is difficult for some members in the supply chain to know whether other members exert effort to improve product quality. Therefore, members in the supply chain cannot make a completely rational decision. In order to overcome the defect of traditional game theory, which assumes that supply chain members are completely rational, the evolutionary game theory is developed as a means to predict the expected distribution of individual behaviors in a biological system with a single species that evolves under natural selection [28]. Smith and Price [29] first put forward an evolutionary stable strategy (ESS), which is defined as a strategy $S^{*}$ satisfying the following two conditions: (1) $E\left(S^{*}, S^{*}\right) \geq E\left(S, S^{*}\right)$ for all $S \neq S^{*}$ and (2) $E\left(S^{*}, S\right)>E(S, S)$ when equality in the first condition holds, where $E$ is the payoff function [30]. The replicator dynamics is proposed by Taylor and Jonker [31], the basic idea of which is that if one strategy gains more than the average income of other strategies during the game process, then it indicates that the strategy is suitable for the evolution of the group [32]. Some researchers have applied evolutionary game theory to study low-carbon scenarios [33, 34], pollution regulation $[35,36]$, enterprises' cooperation and competition in the supply chain [37-39], and so on. For example, $\mathrm{He}$ et al. [32] study an effective green incentive mechanism for the government to promote green tourism development by establishing a three-party dynamic evolutionary game model. So far, few researchers have employed the evolutionary game theory to study food quality. Ma [40] researches the quality control issue in the food supply chain by establishing a dynamic evolutionary game model. $\mathrm{Xu}$ et al. [41] analyze the investment decisions of suppliers and manufacturers in food safety based on an evolutionary game. Cao et al. [42] analyze the influence and authenticity of new media on the decision-making results of the government and food enterprises by establishing an asymmetric evolutionary game. Su et al. [43] discuss the influence of the trilateral evolutionary game on the quality of agrifood under the farmer-supermarket direct purchase mode. However, the above studies ignored the quality effort level of supply chain members. Compared with the previous studies mentioned above, the possible innovations of our research include the following three points: First, the payment matrix is constructed by introducing two kinds of ratios of the input to the output. Second, this paper studies the quality-improving 
input from the perspective of quality effort levels, which is the key innovation. Third, we analyze the evolutionary stable strategy (ESS) of the system under a punishment mechanism, and numerical simulation is presented under different degrees of punishment.

The rest of this paper is organized as follows: Section 2 introduces the basic assumptions, parameters, and variables. Section 3 constructs a model and analyzes the decisionmaking strategies of suppliers and producers. Section 4 analyzes the evolutionary behaviors of players under a penalty mechanism. A numerical simulation is presented in Section 5. Finally, conclusions and future work are presented.

\section{Research Assumptions}

Assume that there are only two kinds of participants in the food supply chain: The first group is the suppliers who are engaged in the production of food raw materials. Qualityimproving efforts of suppliers include actively developing quality management and supervision systems, strictly implementing production safety standards, introducing more advanced production equipment, and investing refrigeration facilities. The second group is the producers who are engaged in the production of food. Quality-improving efforts of producers include the purchase of food testing equipment, traceability system software, and hardware and safety production training. The pure strategy set of the supplier and producer consists of two alternative strategies: quality-improving effort $(\mathrm{QE})$ and no effort (NE). The supplier adopts the QE strategy with the probability of $x(0 \leq x \leq 1)$ and the NE strategy with $1-x$. Similarly, the probability of the producer choosing the QE strategy is $y(0 \leq y \leq 1)$, and the probability of NE is $1-y$.

Hypothesis 1. When neither supplier nor producer makes quality-improving efforts, the food supply chain can only provide products that meet the basic qualification requirements. $R_{1}$ and $R_{2} \quad\left(R_{1}>0\right.$ and $\left.R_{2}>0\right)$, respectively, represent the supplier's profit and producer's profit without effort input.

Hypothesis 2. When only the supplier in the supply chain exerts effort, his/her effort improves the quality of raw materials, which will help to improve food quality. It is assumed that market demands are related to the quality of the product and consumers buy high-quality food at a high price. With the improvement of product quality, market demands will increase. The supplier's profit is $R_{1}+\alpha_{0} e_{1}-C_{1}$, where $e_{1}$ represents the supplier's effort input, $\alpha_{0}\left(0<\alpha_{0}<1\right)$ represents the ratio of the input to the output of the supplier, and $C_{1}$ represents the cost of the supplier's efforts. Because of the effort of the supplier, the producer can obtain a supernormal benefit $T_{2}\left(T_{2}>R_{2}\right)$ by free-riding.

Hypothesis 3. When only the producer in the supply chain exerts quality-improving effort, his/her effort improves the quality of production and processing which will help to improve the food quality. Similarly, the producer's profit is $R_{2}+\beta_{0} e_{2}-C_{2}$, where $e_{2}$ represents the producer's effort input, $\beta_{0}\left(0<\beta_{0}<1\right)$ represents the ratio of the input to the output of the producer, and $C_{2}$ represents the cost of the producer's effort. Because of the effort of the producer, the supplier can obtain a supernormal benefit $T_{1}\left(T_{1}>R_{1}\right)$ by free-riding.

Hypothesis 4. When both sides exert effort together to improve the quality of products, the quality of products has been greatly improved. With the further improvement of product quality, the market demands will increase even more. Consumers will buy high-quality food products at a higher price. Their earnings are expressed as $R_{1}+\alpha_{1} e_{1}-$ $C_{1}$ and $R_{2}+\beta_{1} e_{2}-C_{2}$, respectively, where $\alpha_{1}\left(\alpha_{1} \geq \alpha_{0}\right)$ represents the ratio of the input to the output of the supplier when both sides exert effort together and $\beta_{1}\left(\beta_{1} \geq \beta_{0}\right)$ represents the ratio of the input to the output of the producer when both sides exert effort together.

\section{Game Model}

3.1. The Model. Regarding the above assumption, the payoff of the supplier and the producer is presented in Table 1.

In terms of the parameters in Table 1, the expected return of the supplier choosing the QE and NE strategies is

$$
\begin{aligned}
& U_{11}=y\left(R_{1}+\alpha_{1} e_{1}-C_{1}\right)+(1-y)\left(R_{1}+\alpha_{0} e_{1}-C_{1}\right), \\
& U_{12}=y T_{1}+(1-y) R_{1},
\end{aligned}
$$

where $U_{11}$ represents the expected return of the supplier for the QE strategy and $U_{12}$ represents the expected return of the supplier for the NE strategy. Thus, the average expected return of the supplier is

$$
\bar{U}_{1}=x U_{11}+(1-x) U_{12} .
$$

Thus, the replicated dynamic equation of the supplier's evolutionary strategy is

$$
\begin{aligned}
\dot{x}= & \frac{\mathrm{d} x}{\mathrm{~d} t}=x\left(U_{11}-\bar{U}_{1}\right)=x(1-x)\left(\alpha_{0} e_{1}-C_{1}\right. \\
& \left.+y\left(R_{1}-T_{1}-\left(\alpha_{0}-\alpha_{1}\right) e_{1}\right)\right) .
\end{aligned}
$$

Similarly, the expected return of the producer choosing the $\mathrm{QE}$ and $\mathrm{NE}$ strategies is

$$
\begin{aligned}
& U_{21}=x\left(R_{2}+\beta_{1} e_{2}-C_{2}\right)+(1-x)\left(R_{2}+\beta_{0} e_{2}-C_{2}\right), \\
& U_{22}=x T_{2}+(1-x) R_{2},
\end{aligned}
$$

where $U_{21}$ represents the expected return of the producer for the QE strategy and $U_{22}$ represents the expected return of the producer for the NE strategy. Thus, the average expected return of the producer is

$$
\bar{U}_{2}=y U_{21}+(1-y) U_{22} .
$$

Thus, the replicated dynamic equation of the producer's evolutionary strategy is 
TABle 1: Payoff matrix.

\begin{tabular}{lcr}
\hline Supplier & QE & Producer \\
& $\mathrm{NE}$ & $R_{1}+\alpha_{0} e_{1}-C_{1}, T_{2}$ \\
$\mathrm{QE}$ & $R_{1}+\alpha_{1} e_{1}-C_{1}, R_{2}+\beta_{1} e_{2}-C_{2}$ & $R_{1}, R_{2}$ \\
$\mathrm{NE}$ & $T_{1}, R_{2}+\beta_{0} e_{2}-C_{2}$ & \\
\hline
\end{tabular}

$$
\begin{aligned}
\dot{y}= & \frac{d y}{d t}=y\left(U_{21}-\bar{U}_{2}\right)=y(1-y)\left(\beta_{0} e_{2}-C_{2}\right. \\
& \left.+x\left(R_{2}-T_{2}-\left(\beta_{0}-\beta_{1}\right) e_{2}\right)\right) .
\end{aligned}
$$

The two-dimensional dynamic autonomy system I consisting of formulas (3) and (6) can be expressed as

$$
\left\{\begin{array}{l}
\frac{\mathrm{d} x}{\mathrm{~d} t}=x(1-x)\left(\alpha_{0} e_{1}-C_{1}+y\left(R_{1}-T_{1}-\left(\alpha_{0}-\alpha_{1}\right) e_{1}\right)\right) \\
\frac{\mathrm{d} y}{\mathrm{~d} t}=y(1-y)\left(\beta_{0} e_{2}-C_{2}+x\left(R_{2}-T_{2}-\left(\beta_{0}-\beta_{1}\right) e_{2}\right)\right) .
\end{array}\right.
$$

Proposition 1. The equilibrium points of system I are $O(0,0)$, $A(0,1), B(1,0)$, and $C(1,1)$. When $\left(C_{1} / e_{1}\right)<\alpha_{0}<\alpha_{1}<\left(\left(T_{1}-\right.\right.$ $\left.\left.R_{1}+C_{1}\right) / e_{1}\right)$ and $\left(C_{2} / e_{2}\right)<\beta_{0}<\beta_{1}<\left(\left(T_{2}-R_{2}+C_{2}\right) / e_{2}\right)$ are satisfied, $D\left(x^{*}, y^{*}\right)$ is the equilibrium point.

$$
\begin{aligned}
& x^{*}=\frac{\beta_{0} e_{2}-C_{2}}{T_{2}+\left(\beta_{0}-\beta_{1}\right) e_{2}-R_{2}}, \\
& y^{*}=\frac{\alpha_{0} e_{1}-C_{1}}{T_{1}+\left(\alpha_{0}-\alpha_{1}\right) e_{1}-R_{1}} .
\end{aligned}
$$

Proof. Let equation (3) $=0$ and equation $(6)=0$, then we can get the equilibrium points $O(0,0), A(0,1), B(1,0)$, and $C(1,1)$. When $\left(C_{1} / e_{1}\right)<\alpha_{0}<\alpha_{1}<\left(\left(T_{1}-R_{1}+C_{1}\right) / e_{1}\right)$ and $\left(C_{2} / e_{2}\right)$ $<\beta_{0}<\beta_{1}<\left(\left(T_{2}-R_{2}+C_{2}\right) / e_{2}\right)$ are satisfied, we obtain $0<\left(\beta_{0} e_{2}-C_{2}\right) /\left(T_{2}+\left(\beta_{0}-\beta_{1}\right) e_{2}-R_{2}\right)<1$ and $0<\left(\alpha_{0} e_{1}-\right.$ $\left.C_{1}\right) /\left(T_{1}+\left(\alpha_{0}-\alpha_{1}\right) e_{1}-R_{1}\right)<1$. Therefore, $D\left(x^{*}, y^{*}\right)$ is the equilibrium point.

According to Friedman's research method [44], the evolutionary stable strategy (ESS) can be judged by the following criteria:

$$
\begin{aligned}
\operatorname{det}(J) & =\left|\begin{array}{ll}
a_{11} & a_{12} \\
a_{21} & a_{22}
\end{array}\right|=a_{11} a_{22}-a_{12} a_{21}>0, \\
\operatorname{tr}(J) & =a_{11}+a_{22}<0 .
\end{aligned}
$$

The Jacobian matrix of system I is as follows:

$$
J=\left[\begin{array}{ll}
a_{11} & a_{12} \\
a_{21} & a_{22}
\end{array}\right]=\left[\begin{array}{cc}
(1-2 x)\left(\alpha_{0} e_{1}-C_{1}+y\left(R_{1}-T_{1}-\left(\alpha_{0}-\alpha_{1}\right) e_{1}\right)\right) & x(1-x)\left(R_{1}-T_{1}-\left(\alpha_{0}-\alpha_{1}\right) e_{1}\right) \\
y(1-y)\left(R_{2}-T_{2}-\left(\beta_{0}-\beta_{1}\right) e_{2}\right) & (1-2 y)\left(\beta_{0} e_{2}-C_{2}+x\left(R_{2}-T_{2}-\left(\beta_{0}-\beta_{1}\right) e_{2}\right)\right)
\end{array}\right]
$$

The value of the matrix determinant $J$ is

$$
\begin{aligned}
\operatorname{det} J= & (1-2 x)\left(\alpha_{0} e_{1}-C_{1}+y\left(R_{1}-T_{1}-\left(\alpha_{0}-\alpha_{1}\right) e_{1}\right)\right) \\
& \cdot(1-2 y)\left(\beta_{0} e_{2}-C_{2}+x\left(R_{2}-T_{2}-\left(\beta_{0}-\beta_{1}\right) e_{2}\right)\right) \\
& -x(1-x)\left(R_{1}-T_{1}-\left(\alpha_{0}-\alpha_{1}\right) e_{1}\right) y(1-y) \\
& \cdot\left(R_{2}-T_{2}-\left(\beta_{0}-\beta_{1}\right) e_{2}\right) .
\end{aligned}
$$

The trace of the matrix $J$ is

$$
\begin{aligned}
\operatorname{tr} J= & (1-2 x)\left(\alpha_{0} e_{1}-C_{1}+y\left(R_{1}-T_{1}-\left(\alpha_{0}-\alpha_{1}\right) e_{1}\right)\right) \\
& +(1-2 y)\left(\beta_{0} e_{2}-C_{2}+x\left(R_{2}-T_{2}-\left(\beta_{0}-\beta_{1}\right) e_{2}\right)\right) .
\end{aligned}
$$

3.2. Model Discussion. According to different conditions, we study the local stability of different equilibrium points. There would be five scenarios in the game, which are analyzed as follows.

\subsubsection{Scenario $I$}

Proposition 2. When $0<\alpha_{0}<\left(C_{1} / e_{1}\right), \alpha_{0}<\alpha_{1}<\left(\left(T_{1}-R_{1}\right.\right.$ $\left.\left.+C_{1}\right) / e_{1}\right), 0<\beta_{0}<\left(C_{2} / e_{1}\right)$, and $\beta_{0}<\beta_{1}<\left(\left(T_{2}-R_{2}+C_{2}\right) / e_{2}\right)$ are satisfied, $O(0,0)$ is the ESS point. The behavior strategy is $(\mathrm{NE}, \mathrm{NE})$.

Proof. According to the above method, we can calculate the value of $\operatorname{det} J$ and $\operatorname{tr} J$ for each equilibrium point. The results of four local equilibrium points are shown in Table 2.

Although the quality-improving effort is high, the supplier and producer all get less revenue because ratios of the input to the output $\alpha_{0}, \alpha_{1}, \beta_{0}$, and $\beta_{1}$ are relatively small. Therefore, $O(0,0)$ is an ESS point, $A(0,1)$ and $B(1,0)$ are two 
saddle points, and $C(1,1)$ is an unstable point. The evolutionary path is shown in Figure 1(a).

\subsubsection{Scenario II}

Proposition 3. When $0<\alpha_{0}<\left(C_{1} / e_{1}\right), \alpha_{0}<\alpha_{1}<\left(\left(T_{1}-R_{1}+\right.\right.$ $\left.\left.C_{1}\right) / e_{1}\right)$, and $\left(C_{2} / e_{2}\right)<\beta_{0}<\beta_{1}<\left(\left(T_{2}-R_{2}+C_{2}\right) / e_{2}\right)$ are satisfied, $A(0,1)$ is the ESS point. The behavior strategy is (NE, QE).

Proof. The method is similar to the proof of Proposition 2. The results of four local equilibrium points are shown in Table 3.

The revenue of the producer's quality-improving effort is greater than the cost but less than the free-riding revenue. The revenue of the supplier's effort is less than the cost, so the supplier is reluctant to improve quality. Therefore, $A(0,1)$ is an ESS point, $O(0,0)$ and $B(1,0)$ are two saddle points, and $C(1,1)$ is an unstable point. The evolutionary path is shown in Figure 1(b).

\subsubsection{Scenario III}

Proposition 4. When $\left(C_{1} / e_{1}\right)<\alpha_{0}<\alpha_{1}<\left(\left(T_{1}-R_{1}+C_{1}\right) / e_{1}\right)$, $0<\beta_{0}<\left(C_{2} / e_{2}\right)$, and $\beta_{0}<\beta_{1}<\left(\left(T_{2}-R_{2}+C_{2}\right) / e_{2}\right)$ are satisfied, $B(1,0)$ is the ESS point. The behavior strategy is $(\mathrm{QE}, \mathrm{NE})$.

Proof 4. The method is similar to the proof of Proposition 2. The results of four local equilibrium points are shown in Table 4 .

The revenue of the supplier's effort is greater than the cost but less than the free-riding revenue. The revenue of the producer's quality-improving effort is less than the cost, so the producer is reluctant to improve quality. Therefore, $B(1,0)$ is an ESS point, $O(0,0)$ and $A(0,1)$ are two saddle points, and $C(1,1)$ is an unstable point. The evolutionary path is shown in Figure 1(c).

\subsubsection{Scenario $I V$}

Proposition 5. When $\left(C_{1} / e_{1}\right)<\alpha_{0}<\alpha_{1}<\left(\left(T_{1}-R_{1}+C_{1}\right) /\right.$ $\left.e_{1}\right)$ and $\left(C_{2} / e_{2}\right)<\beta_{0}<\beta_{1}<\left(\left(T_{2}-R_{2}+C_{2}\right) / e_{2}\right)$ are satisfied, $A(0,1)$ and $B(1,0)$ are the ESS points. The behavior strategy is (QE, NE) and (NE, QE). The equilibrium state depends on the initial state of the system.

(i) When the initial state falls into the area ACDO, $A(0$, 1) is the ESS point.

(ii) When the initial state falls into the area BCDO, $B(1$, 0 ) is the ESS point.

Proof. The method is similar to the proof of Proposition 2. The results of five local equilibrium points are shown in Table 5 .
TABLE 2: Evolutionary stability of local equilibrium points in Scenario I.

\begin{tabular}{lccc}
\hline Equilibrium point & $\operatorname{tr} J$ & $\operatorname{det} J$ & State \\
\hline$(0,0)$ & - & + & ESS point \\
$(0,1)$ & Uncertain & - & Saddle point \\
$(1,0)$ & Uncertain & - & Saddle point \\
$(1,1)$ & + & + & Unstable point \\
\hline
\end{tabular}

Both the supplier's revenue and the producer's revenue are greater than the cost but less than the free-riding revenue. Therefore, $A(0,1)$ and $B(1,0)$ are ESS points. $O(0,0)$ and $C(1,1)$ are two unstable points. $D\left(x^{*}, y^{*}\right)$ is the saddle point. The evolutionary path is shown in Figure 1(d). The equilibrium state depends on the initial state of system I. The possibility of the evolutionary result that eventually converges to $A(0,1)$ or $B(1,0)$ is determined by the size of the areas $S_{A}$ (i.e., quadrangle ACDO) and $S_{B}$ (i.e., quadrangle BCDO). When $S_{A}=S_{B}$, the probability of the system which will converge to $A(0,1)$ or $B(1,0)$ is the same. When $S_{A}>S_{B}$, the probability of the system which will converge to $A(0,1)$ is greater than the probability of the system which will converge to $B(1,0)$; that is to say, the supplier will choose the NE strategy and the producer will choose the $\mathrm{QE}$ strategy. When $S_{A}<S_{B}$, the probability of the system which will converge to $B(1,0)$ is greater than the probability of the system which will converge to $A(0,1)$; that is to say, the supplier will choose the QE strategy and the producer will choose the NE strategy.

The size of the area $S_{A}$ is

$$
S_{A}=\frac{1}{2}\left[\frac{\beta_{0} e_{2}-C_{2}}{T_{2}+\left(\beta_{0}-\beta_{1}\right) e_{2}-R_{2}}+\frac{T_{1}-R_{1}+C_{1}-\alpha_{1} e_{1}}{T_{1}+\left(\alpha_{0}-\alpha_{1}\right) e_{1}-R_{1}}\right] \text {. }
$$

According to equation (13), we can draw some important conclusions:

Corollary. The size of the area $S_{A}$ is affected by different parameters and has the following characteristics:

(1) $\left(\partial S_{A} / \partial \alpha_{0}\right)<0,\left(\partial S_{A} / \partial \alpha_{1}\right)<0,\left(\partial S_{A} / \partial \beta_{0}\right)>0$, and $\left(\partial S_{A} / \partial \beta_{1}\right)>0$

(2) $\left(\partial S_{A} / \partial R_{1}\right)<0$ and $\left(\partial S_{A} / \partial R_{2}\right)>0$

(3) $\left(\partial S_{A} / \partial T_{1}\right)>0$ and $\left(\partial S_{A} / \partial T_{2}\right)<0$

(4) $\left(\partial S_{A} / \partial C_{1}\right)>0$ and $\left(\partial S_{A} / \partial C_{2}\right)<0$

Corollary (1) shows that when the ratio of the input to the output of the supplier becomes smaller, and the ratio of the input to the output of the producer become greater, there is a higher probability that the system will converge toward $A(0,1)$. Corollary (2) indicates that when the income of the supplier becomes smaller, and the income of the producer becomes higher, there is a higher probability that the system will converge toward $A(0,1)$. Otherwise, there is a higher probability that the system will converge toward $B(1,0)$. Corollary (3) shows that when the income of free-riding for the supplier becomes larger, and the income of free-riding for the producer becomes smaller, there is a higher probability that the system will converge toward $A(0,1)$. Otherwise, there is a higher probability that the system will converge 


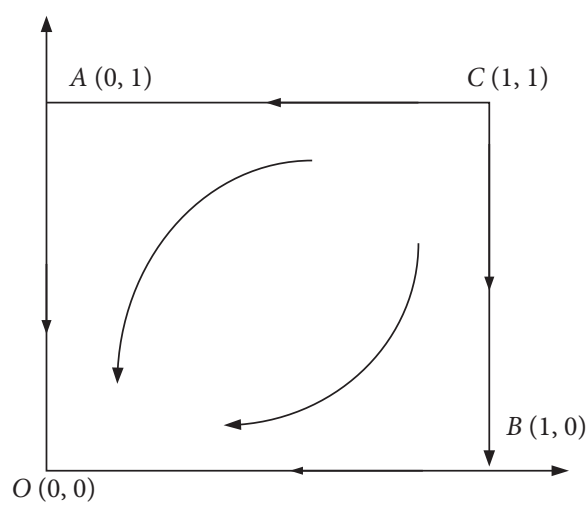

(a)

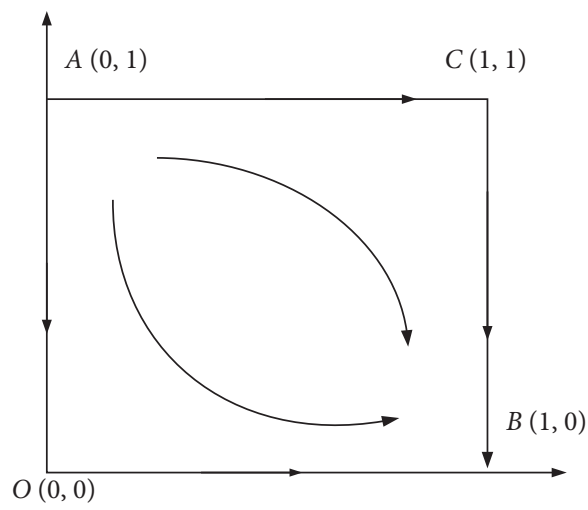

(c)

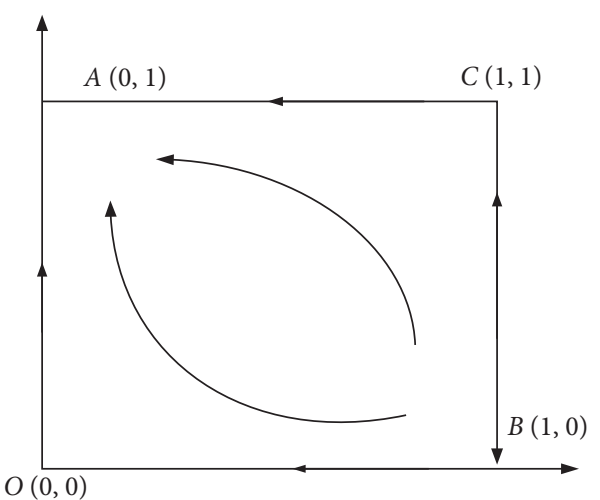

(b)

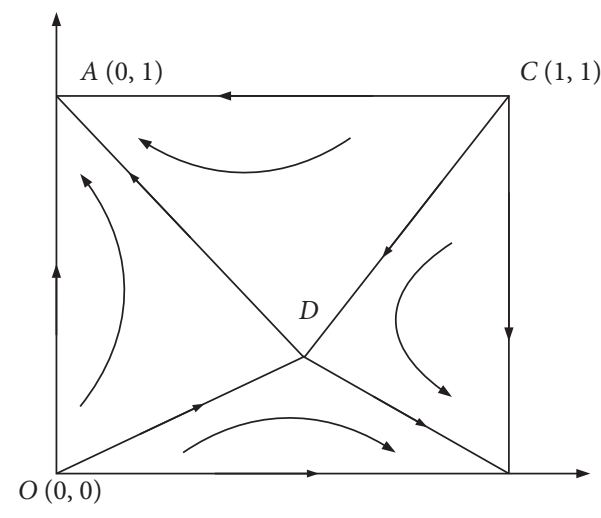

(d)

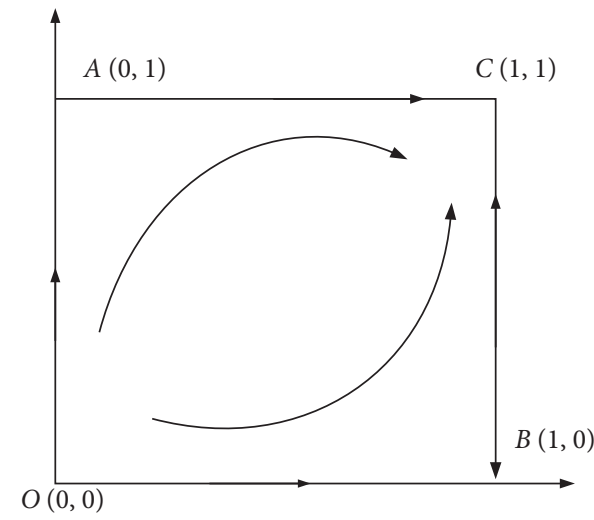

(e)

Figure 1: Phase diagrams of the evolutionary game.

TABLE 3: Evolutionary stability of local equilibrium points in Scenario II.

\begin{tabular}{lccc}
\hline Equilibrium point & $\operatorname{tr} J$ & $\operatorname{det} J$ & State \\
\hline$(0,0)$ & Uncertain & - & Saddle point \\
$(0,1)$ & - & + & ESS point \\
$(1,0)$ & Uncertain & - & Saddle point \\
$(1,1)$ & + & + & Unstable point \\
\hline
\end{tabular}

toward $B(1,0)$. Corollary (4) indicates that when the cost of the supplier becomes larger, and the cost of the producer becomes smaller, there is a higher probability that the system
TABLE 4: Evolutionary stability of local equilibrium points in Scenario III.

\begin{tabular}{lccc}
\hline Equilibrium point & $\operatorname{tr} J$ & $\operatorname{det} J$ & State \\
\hline$(0,0)$ & Uncertain & - & Saddle point \\
$(0,1)$ & Uncertain & - & Saddle point \\
$(1,0)$ & - & + & ESS point \\
$(1,1)$ & + & + & Unstable point \\
\hline
\end{tabular}

will converge toward $A(0,1)$. Otherwise, there is a higher probability that the system will converge toward $B(1,0)$. The specific calculation process is presented in Appendix. 
TABLE 5: Evolutionary stability of local equilibrium points in Scenario IV.

\begin{tabular}{lccc}
\hline Equilibrium point & $\operatorname{tr} J$ & $\operatorname{det} J$ & State \\
\hline$(0,0)$ & + & + & Unstable point \\
$(0,1)$ & - & + & ESS point \\
$(1,0)$ & - & + & ESS point \\
$(1,1)$ & + & + & Unstable point \\
$\left(x^{*}, y^{*}\right)$ & & + & Saddle point \\
\hline
\end{tabular}

\subsubsection{Scenario $V$}

Proposition 6. When $\left(\left(T_{1}-R_{1}+C_{1}\right) / e_{1}\right)<\alpha_{0}<\alpha_{1}$ and $\left(\left(T_{2}-R_{2}+C_{2}\right) / e_{2}\right)<\beta_{0}<\beta_{1}$ are satisfied, $(1,1)$ is the ESS point. The behavior strategy is $(\mathrm{QE}, \mathrm{QE})$.

Proof 6. The method is similar to the proof of Proposition 2. The results of four local equilibrium points are shown in Table 6.

The revenue of the producer's quality-improving effort is greater than the cost, and the revenue of the supplier's quality-improving effort is greater than the cost. Therefore, suppliers and producers are willing to exert effort to improve product quality. Therefore, $C(1,1)$ is an ESS point, $A(0,1)$ and $B(1,0)$ are two saddle points, and $O(0,0)$ is an unstable point. The evolutionary path is shown in Figure 1(e).

\section{Analysis of Evolutionary Game under Punishment Mechanism}

According to the above analysis results, when the ratios of the input to the output $\alpha_{0}, \alpha_{1}, \beta_{0}$, and $\beta_{1}$ are relatively small, and the benefit of the player is less than the cost, or the benefit of the player is greater than the cost but less than the free-riding benefit, the player is reluctant to choose the $\mathrm{QE}$ strategy. In this case, government regulation is necessary. Suppose that the player choosing free-riding will be punished $P$ by the government. If both sides are reluctant to exert quality-improving efforts, neither is punished. The payoff under the punishment mechanism is presented in Table 7.

The two-dimensional dynamic autonomy system II can be expressed as

$$
\left\{\begin{array}{l}
\frac{\mathrm{d} x}{\mathrm{~d} t}=x(1-x)\left(\alpha_{0} e_{1}-C_{1}+y\left(R_{1}-T_{1}+P-\left(\alpha_{0}-\alpha_{1}\right) e_{1}\right)\right), \\
\frac{\mathrm{d} y}{\mathrm{~d} t}=y(1-y)\left(\beta_{0} e_{2}-C_{2}+x\left(R_{2}-T_{2}+P-\left(\beta_{0}-\beta_{1}\right) e_{2}\right)\right) .
\end{array}\right.
$$

Proposition 7. The equilibrium points of the replicator dynamic system are $O(0,0), A(0,1), B(1,0)$, and $C(1,1)$. If and only if $0<P<\min \left(T_{2}-R_{2}+C_{2}-\beta_{1} e_{2}, T_{1}-R_{1}+\right.$ $\left.C_{1}-\alpha_{1} e_{1}\right), D\left(x^{*}, y^{*}\right)$ is the equilibrium point.
TABLE 6: Evolutionary stability of local equilibrium points in Scenario V.

\begin{tabular}{lccc}
\hline Equilibrium point & $\operatorname{tr} J$ & $\operatorname{det} J$ & State \\
\hline$(0,0)$ & + & + & Unstable point \\
$(0,1)$ & Uncertain & - & Saddle point \\
$(1,0)$ & Uncertain & - & Saddle point \\
$(1,1)$ & - & + & ESS point \\
\hline
\end{tabular}

TABLe 7: Payoff matrix under the punishment mechanism.

\begin{tabular}{lcc}
\hline Supplier & \multicolumn{2}{c}{ Producer } \\
& $\mathrm{QE}$ & $\mathrm{NE}$ \\
\hline $\mathrm{QE}$ & $R_{1}+\alpha_{1} e_{1}-C_{1}, R_{2}+\beta_{1} e_{2}-C_{2}$ & $R_{1}+\alpha_{0} e_{1}-C_{1}, T_{2}-P$ \\
$\mathrm{NE}$ & $T_{1}-P, R_{2}+\beta_{0} e_{2}-C_{2}$ & $R_{1}, R_{2}$ \\
\hline
\end{tabular}

$$
\begin{aligned}
& x^{*}=\frac{\beta_{0} e_{2}-C_{2}}{T_{2}+\left(\beta_{0}-\beta_{1}\right) e_{2}-R_{2}-P}, \\
& y^{*}=\frac{\alpha_{0} e_{1}-C_{1}}{T_{1}+\left(\alpha_{0}-\alpha_{1}\right) e_{1}-R_{1}-P} .
\end{aligned}
$$

Proposition 8. The necessary and sufficient condition that $D(1,1)$ is the only ESS point of system II is $P>\max \left(T_{1}+C_{1}-R_{1}-\alpha_{1} e_{1}, C_{2}+T_{2}-R_{2}-\beta_{1} e_{2}\right)$.

Proof 8. According to data in Table 8, the necessary and sufficient condition that $D(1,1)$ is the only ESS point of system II is $\operatorname{det} J>0$ and $\operatorname{tr} J<0$. That is, $-\left(R_{1}-T_{1}+P-\right.$ $\left.C_{1}+\alpha_{1} e_{1}\right)-\left(R_{2}-T_{2}+P-C_{2}+\beta_{1} e_{2}\right)<0$ and $\left(R_{1}-T_{1}+P-\right.$ $\left.C_{1}+\alpha_{1} e_{1}\right)\left(R_{2}-T_{2}+P-C_{2}+\beta_{1} e_{2}\right)>0$. Therefore, we can get $\left(R_{1}-T_{1}+P-C_{1}+\alpha_{1} e_{1}\right)>0$ and $\left(R_{2}-T_{2}+P-C_{2}+\right.$ $\left.\beta_{1} e_{2}\right)>0$. Therefore, $P>\max \left(T_{1}+C_{1}-R_{1}-\alpha_{1} e_{1}, C_{2}+T_{2}-\right.$ $R_{2}-\beta_{1} e_{2}$ ).

This proposition represents that when $P>\max \left(T_{1}+C_{1}-R_{1}-\alpha_{1} e_{1}, C_{2}+T_{2}-R_{2}-\beta_{1} e_{2}\right)$ is satisfied, the evolutionary stable strategy (ESS) point of system II is $C(1,1)$. That is to say, the penalty imposed by the government is greater than the difference between the benefits of the free-riding of the supplier or producer and the benefits of the supplier- or producer-exerted effort to improve the quality. Suppliers and producers are willing to work together to improve product quality because the government's punishment is very high. Therefore, if the government increases the penalty for players, it will make the free-riding behavior unprofitable and thus reduce the opportunistic behavior of both sides.

\section{Numerical Simulation}

In order to further understand the influence of the initial value, different factors, and government regulation, the numerical experiment is conducted to observe changes in strategic choices of the supplier and producer under different initial values, parameter values, and degrees of government penalty. 
TABLE 8: Values of $a_{11}, a_{12}, a_{21}$, and $a_{22}$ at the local stable equilibrium point.

\begin{tabular}{|c|c|c|c|c|}
\hline Equilibrium point & $a_{11}$ & $a_{12}$ & $a_{21}$ & $a_{22}$ \\
\hline$(0,0)$ & $\alpha_{0} e_{1}-C_{1}$ & 0 & 0 & $\beta_{0} e_{2}-C_{2}$ \\
\hline$(0,1)$ & $R_{1}-T_{1}+P-C_{1}+\alpha_{1} e_{1}$ & 0 & 0 & $-\left(\beta_{0} e_{2}-C_{2}\right)$ \\
\hline$(1,0)$ & $-\left(\alpha_{0} e_{1}-C_{1}\right)$ & 0 & 0 & $R_{2}-T_{2}+P-C_{2}+\beta_{1} e_{2}$ \\
\hline$(1,1)$ & $-\left(R_{1}-T_{1}+P-C_{1}+\alpha_{1} e_{1}\right)$ & 0 & 0 & $-\left(R_{2}-T_{2}+P-C_{2}+\beta_{1} e_{2}\right)$ \\
\hline
\end{tabular}

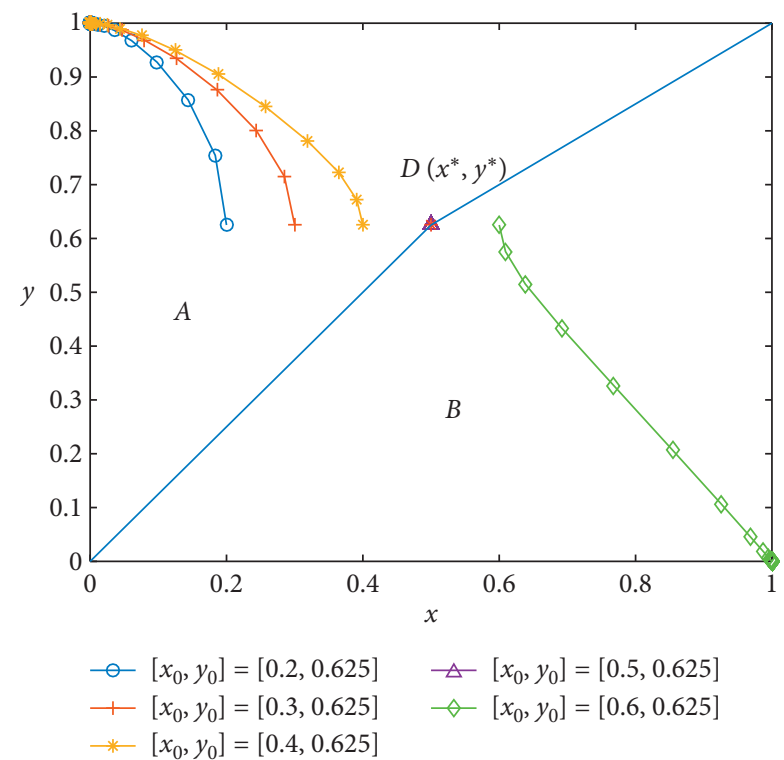

FIgURE 2: Influences of the changes in the initial value $x_{0}$ on the evolutionary result.

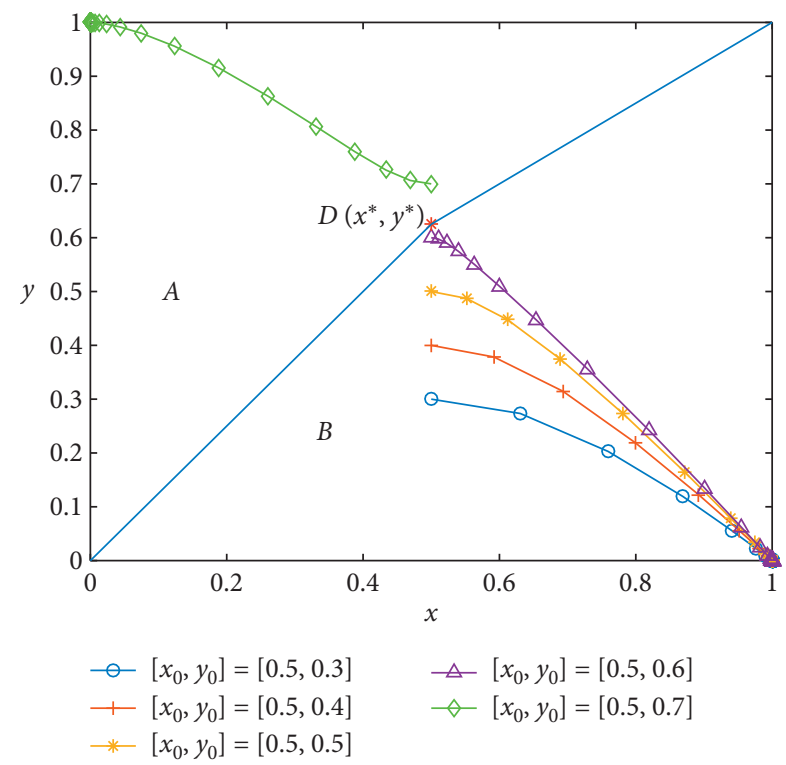

Figure 3: Influences of the changes in the initial value $y_{0}$ on the evolutionary result.

The parameters should conform to the following constraints: $\quad\left(C_{1} / e_{1}\right)<\alpha_{0}<\alpha_{1}<\left(\left(T_{1}-R_{1}+C_{1}\right) / e_{1}\right), \quad\left(C_{2} / e_{2}\right)$ $<\beta_{0}<\beta_{1}<\left(\left(T_{2}-R_{2}+C_{2}\right) / e_{2}\right), C_{1}<R_{1}<T_{1}$, and $C_{2}<R_{2}<$ $T_{2}$. Therefore, we assume the following parameter values:

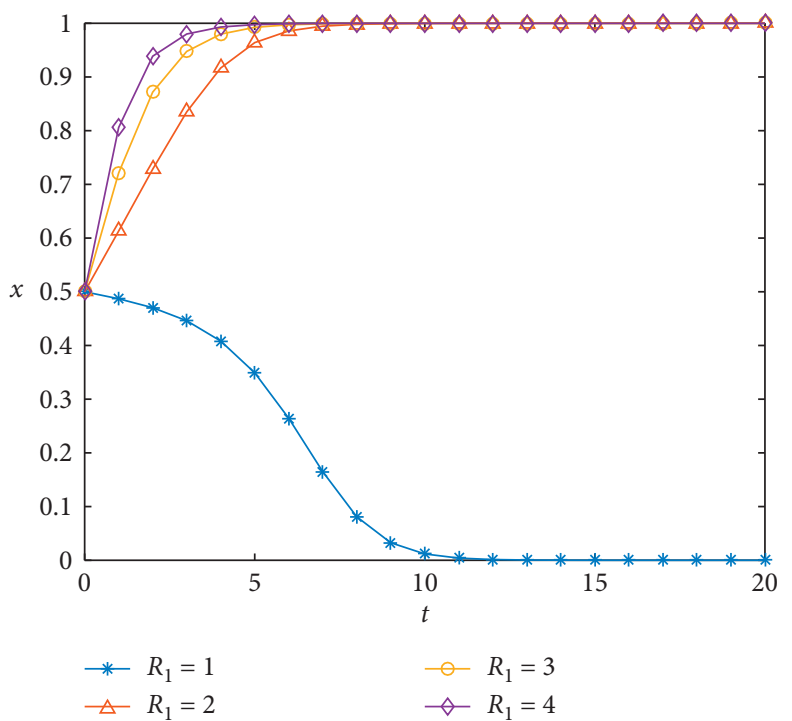

FIGURE 4: Influences of the profit $R_{1}$ on the supplier.

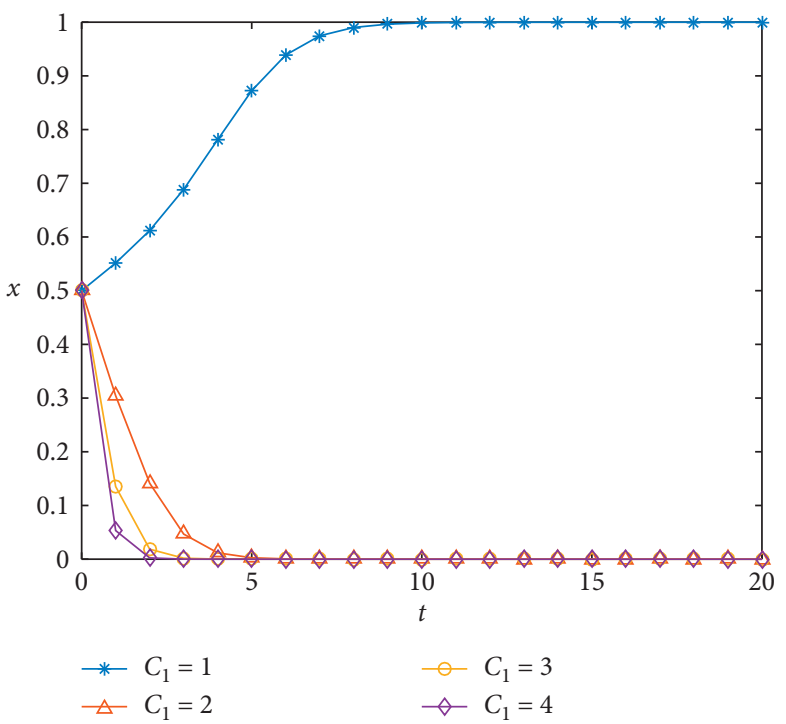

Figure 5: Influences of the cost $C_{1}$ on the supplier.

$C_{1}=1, C_{2}=2, \alpha_{0}=0.5, \alpha_{1}=0.6, \beta_{0}=0.6, \beta_{1}=0.7, e_{1}=4$, $e_{2}=5, R_{1}=1.5, T_{1}=3.5, R_{2}=2.5$, and $T_{2}=5$. According to the above parameters, the saddle point of the evolutionary game can be obtained as $\left(x^{*}, y^{*}\right)=(0.5,0.625)$.

5.1. Influence of the Initial Value on Evolutionary Results. Assuming that other parameters are constant, we study the effect of the initial value $\left(x_{0}, y_{0}\right)$ changes on the evolutionary 


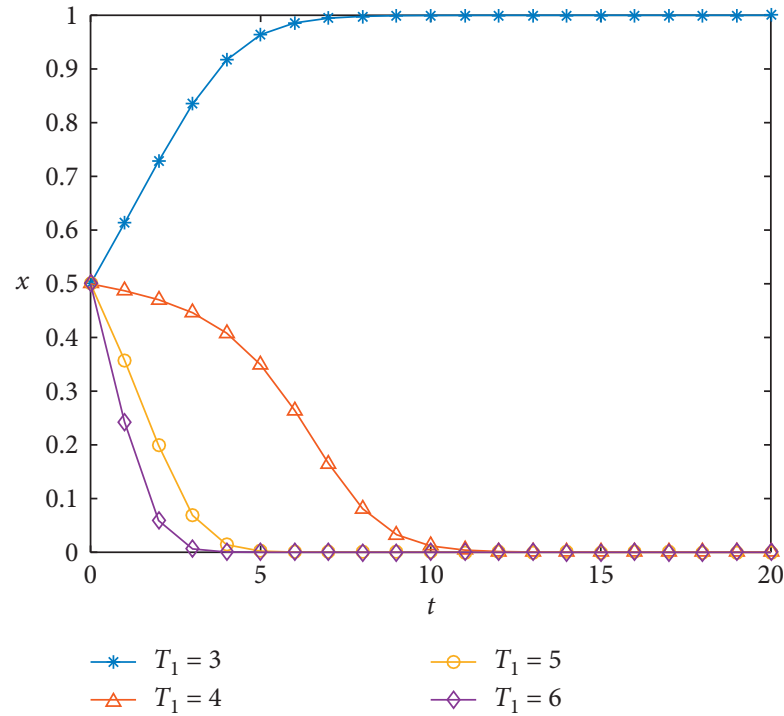

Figure 6: Influences of the free-riding benefit $T_{1}$ on the supplier.

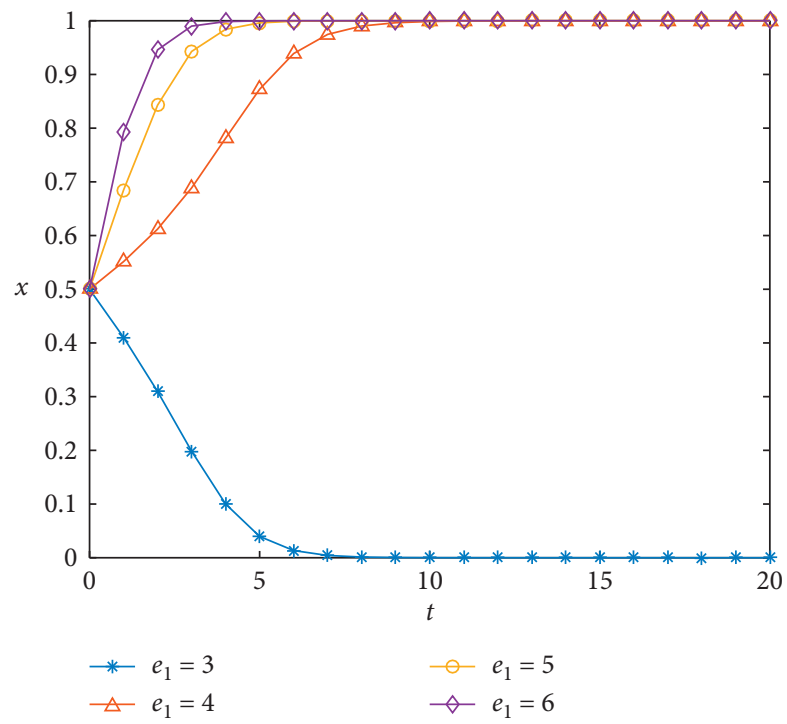

FIGURE 7: Influences of the quality-improving effort input $e_{1}$ on the supplier.

results. In the case of $y_{0}=0.625, x_{0}$ takes the values $0.2,0.3$, $0.4,0.5$, and 0.6. When $x_{0}=0.2,0.3,0.4(<0.5)$, the system evolves to the state $A(0,1)$. When $x_{0}=0.6(>0.6)$, the system state changes from $A(0,1)$ to $B(1,0)$, as shown in Figure 2.

In the case of $x_{0}=0.5, y_{0}$ takes the values $0.3,0.4,0.5,0.6$, and 0.7 . When $y_{0}=0.3,0.4,0.5,0.6$, the system state evolves to the state $B(1,0)$. When $y_{0}=0.7$, the system state changes from $B(1,0)$ to $A(0,1)$, as shown in Figure 3 . Based on the above analysis, we can see that whether the system eventually converges to $A(0,1)$ or $B(1,0)$ depends on the initial state of the system. When the initial state falls into region $A$, the system will converge to $A(0,1)$. When the initial state falls into region $\mathrm{B}$, the system will converge to $B(1,0)$. The results show that if the quality effort of the supplier or the producer exceeds a certain threshold, the participants will change to

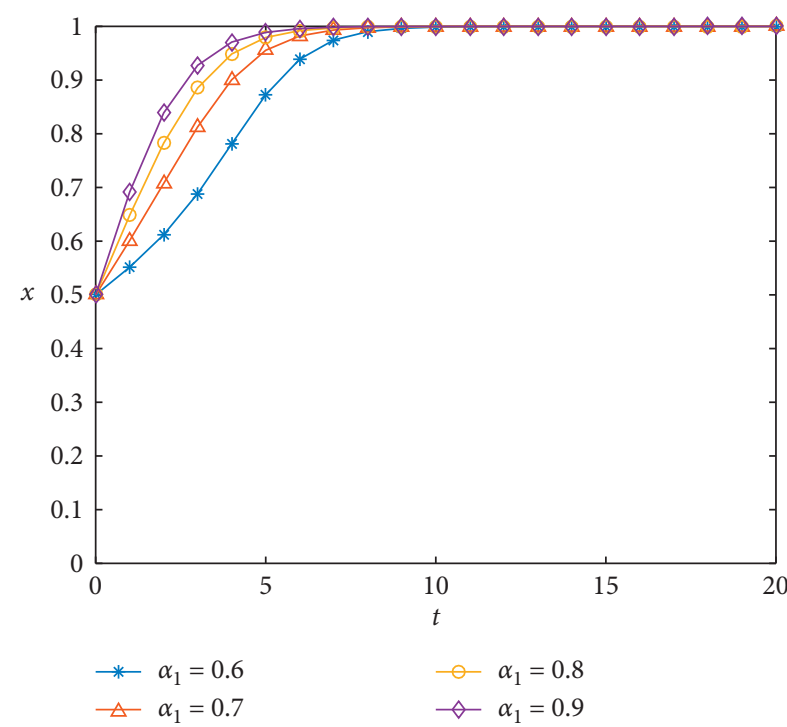

FIGURE 8: Influences of the ratio of the input to the output $\alpha_{1}$ on the supplier.

the free-rider state, which indicates that the behavior strategies between suppliers and producers influence each other.

5.2. Influence of Factors on Evolutionary Results. Since the supplier and producer are similar, this paper only takes supplier as an example to analyze the influence of factor changes on the supplier's effort strategies. Supposing that other factors are constant, we analyze the influence of $R_{1}=1$, $2,3,4$ on the evolutionary results of the suppliers' strategy. Figure 4 shows that, with the increase of income $R_{1}$, the rate of the suppliers choosing the QE strategy will increase quickly. The result shows that if the food suppliers get considerable income without quality input, they can afford a large number of funds to quality input and take the risk of quality input. Suppliers expect to get more income from quality input, so they have more motivation to make quality input.

When other factors are constant, the increase in $C_{1}$ reduces the return on the quality-improving efforts of the supplier. Figure 5 shows that when $C_{1}$ exceeds a certain value, the suppliers choose the NE strategy instead of the QE strategy. At the same time, with the increase of cost $C_{1}$, the rate of the suppliers choosing the NE strategy will increase quickly. The result shows that the supplier adopts an effective management strategy to reduce the cost of the quality input. With the reduction of quality input cost, suppliers are more likely to make quality input.

When other factors are unchanged, the increase of $T_{1}$ curbs the motivation of the supplier to choose the $\mathrm{QE}$ strategy. Figure 6 shows that when $T_{1}$ exceeds a certain value, the suppliers would rather hitchhike instead of choosing the QE strategy. At the same time, with the increase of $T_{1}$, the rate of the suppliers choosing the NE strategy will increase quickly. The result shows that if the hitchhiker can get more benefit from the other side's 


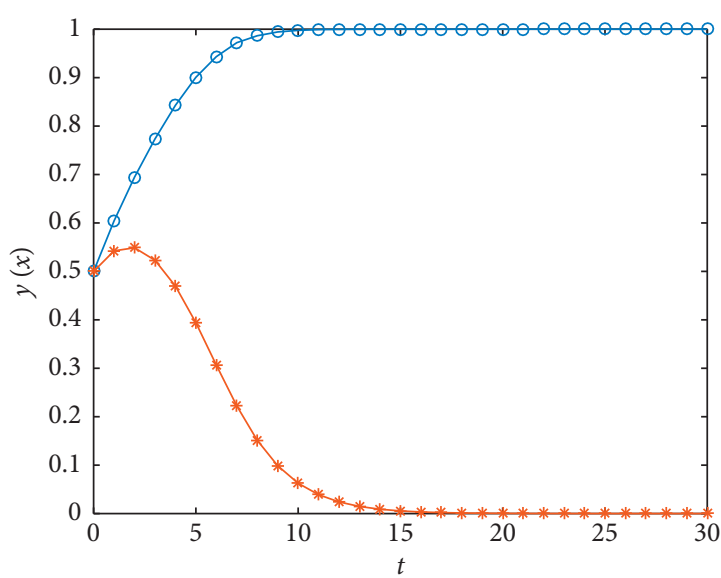

$\rightarrow x$
$\rightarrow-y$

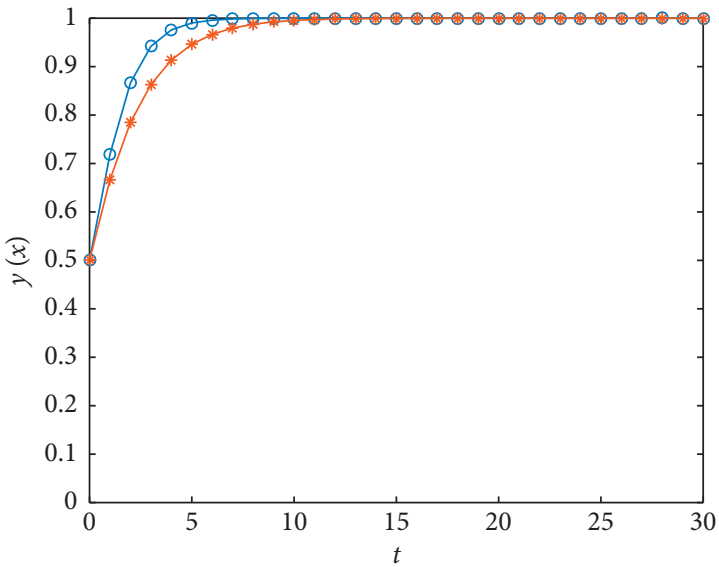

$-x$
$\rightarrow-y$

(a)

(b)

FIgURE 9: Influences of government penalty $P$ on the evolutionary results. (a) $P=0.5$. (b) $P=1.5$.

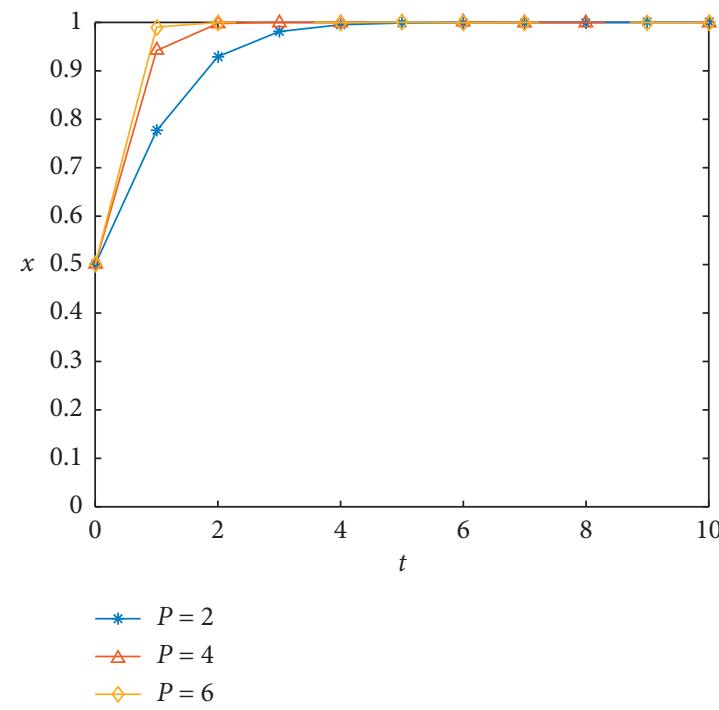

(a)

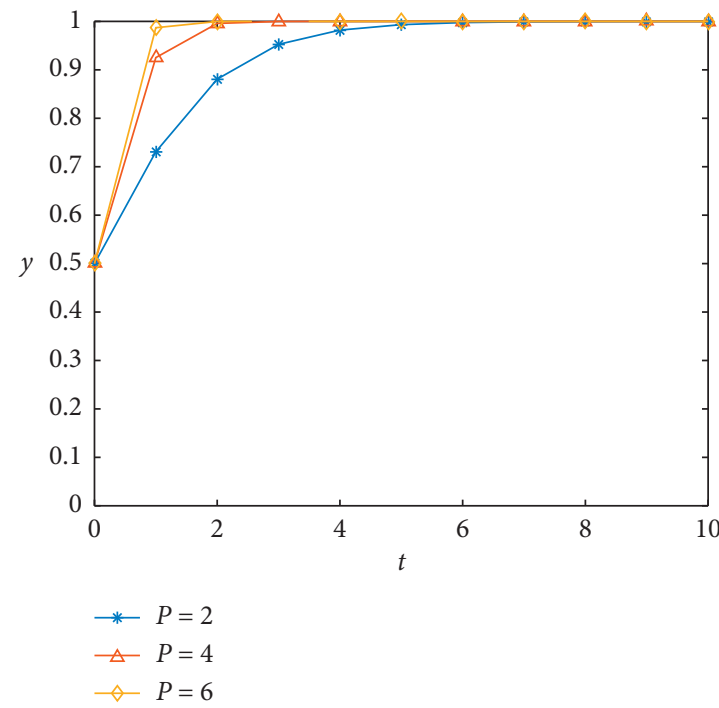

(b)

Figure 10: Influences of government penalty $P$ on the evolutionary results $(P=2,4,6(>1))$.

quality input, the enthusiasm of the hitchhiker's quality input will be greatly reduced.

When other factors remain unchanged, the increase of $e_{1}$ improves the motivation of the supplier to choose the $\mathrm{QE}$ strategy. Figure 7 shows that when $e_{1}$ exceeds a certain value, the suppliers would rather choose the QE strategy instead of the NE strategy. At the same time, with the increase of $e_{1}$, the rate of the suppliers choosing the QE strategy will increase quickly. This shows that, with the increase of the supplier's quality input, the price and market demand will continue to increase. A supplier can get more benefits and gain higher brand loyalty, and then the probability of using quality input by the supplier will be higher. Generally speaking, food enterprises with higher brand loyalty and large market share pay more attention to food safety and have greater motivation to invest in quality because the occurrences of food safety accidents will bring serious consequences to enterprises. For example, the Sanlu milk powder incident in 2008 brought a serious impact on Sanlu Group.

When other factors remain unchanged, the increase of $\alpha_{1}$ improves the motivation of the supplier to choose the QE strategy. Figure 8 shows that, with the increase of $\alpha_{1}$, the rate of the suppliers choosing the QE strategy will increase quickly. This shows that if the supplier adopts effective management strategies to increase the ratio of the input to the output, the quality input cost of the same unit can bring greater benefits to itself, and the probability of quality input by the supplier will be higher. 
5.3. Influence of Government Punishment on the Evolutionary Results. We discuss the influence of government regulation on the evolutionary results. According to Proposition 7, we can obtain the following results: $T_{1}-R_{1}+C_{1}-\alpha_{1} e_{1}=0.6$ and $T_{2}-R_{2}+C_{2}-\beta_{1} e_{2}=1$.

Assuming $P=0.5$, which satisfies the condition $0<P<\min \{0.6,1\}$, we can find that the supplier chooses the QE strategy, while the producer chooses the NE strategy, as shown in Figure 9(a). This verifies Proposition 7.

Assuming $P=1.5$, which satisfies the condition $P>\max \{0.6,1\}$, we can find that both suppliers and producers choose the QE strategy, as shown in Figure 9(b). This verifies Proposition 8.

With other factors being constant, we analyze the influence of $P=2,4,6(>1)$ on the evolutionary results of the supplier's strategy and producer's strategy, as shown in Figure 10. With the increase of punishment $P$, the rate of the supplier and producer choosing the QE strategy will increase quickly.

\section{Conclusions}

Using evolutionary game theory, this paper analyzes the behavior strategy of suppliers and producers considering the quality-improving effort in the food supply chain. The research results show that the behavioral strategies are closely related to the factors such as the ratios of the input to the output, the cost of quality-improving effort, the hitchhiking benefits, and the initial strategy.

The increase of the parameters including the normal profit of participants, the ratio of the input to the output of participants, and the effort input of participants has a promoting effect on the evolution of the system. The decline of the parameters including the cost of quality-improving effort and a free-riding benefit of participants has a promoting effect on the evolution of the system. The government can refer to the model proposed in this research and take corresponding measures to formulate the best food regulation policy.

If the free-riding behavior of one participant gains a large benefit, then no one in the food supply chain is willing to make efforts to improve quality. Under this situation, the government needs to impose a penalty on hitchhikers to ensure food safety. Only when the punishment exceeds a certain threshold, suppliers and producers can work together to improve the quality of the product. Furthermore, the greater the intensity of regulation punishment is, the faster the system evolves into a stable state.

It can be seen that the ratios of the input to the output of the supplier and producer are important factors which influence the direction of the game system evolution. The ratio of the input to the output influences the benefits of the quality-improving effort of both sides, which further influences the choice of the effort input or free-riding behavior. The greater the ratio of the input to the output of the participant is, the more the participant chooses to exert the quality-improving effort. Therefore, the government should actively guide food enterprises to strengthen industry-university-research technology cooperation and support enterprises to reduce investment risks through policies such as achievements transformation and tax incentives. By improving the technology and management level, food enterprises improve the ratio of the input to the output.

This paper only considers the impact of price and quantity changes on quality-improving effort. However, it ignores the volatility of the market, the changes in consumers' income, and the market competition. Moreover, this study does not consider the possible coordination and incentive problems between suppliers and producers in the food supply chain. Therefore, how to design a reasonable contract to motivate participants in the supply chain is an important direction in future research.

\section{Appendix}

\section{Inference A.1}

Proof. $S_{A}$ takes the first derivative of $\alpha_{0}, \alpha_{1}, \beta_{0}$, and $\beta_{1}$. Thus, we can obtain

$$
\begin{aligned}
& \frac{\partial S_{A}}{\partial \alpha_{0}}=\frac{-e_{1}\left(T_{1}-R_{1}+C_{1}-\alpha_{1} e_{1}\right)}{2\left[T_{1}+\left(\alpha_{0}-\alpha_{1}\right) e_{1}-R_{1}\right]^{2}}<0, \\
& \frac{\partial S_{A}}{\partial \alpha_{1}}=\frac{-e_{1}\left(\alpha e_{1}-C_{1}\right)}{2\left[T_{1}+\left(\alpha_{0}-\alpha_{1}\right) e_{1}-R_{1}\right]^{2}}<0, \\
& \frac{\partial S_{A}}{\partial \beta_{0}}=\frac{e_{2}\left(T_{2}-R_{2}-\beta_{1} e_{2}+C_{2}\right)}{2\left[T_{2}+\left(\beta_{0}-\beta_{1}\right) e_{2}-R_{2}\right]^{2}}>0, \\
& \frac{\partial S_{A}}{\partial \beta_{1}}=\frac{e_{2}\left(\beta_{0} e_{2}-C_{2}\right)}{2\left[T_{2}+\left(\beta_{0}-\beta_{1}\right) e_{2}-R_{2}\right]^{2}}>0 .
\end{aligned}
$$

\section{Inference A.2}

Proof. $S_{A}$ takes the first derivative of $R_{1}$ and $R_{2}$. Thus, we can obtain

$$
\begin{aligned}
& \frac{\partial S_{A}}{\partial R_{1}}=\frac{C_{1}-\alpha_{0} e_{1}}{2\left[T_{1}+\left(\alpha_{0}-\alpha_{1}\right) e_{1}-R_{1}\right]^{2}}<0, \\
& \frac{\partial S_{A}}{\partial R_{2}}=\frac{\beta_{0} e_{2}-C_{2}}{2\left[T_{2}+\left(\beta_{0}-\beta_{1}\right) e_{2}-R_{2}\right]^{2}}>0 .
\end{aligned}
$$

Inference A.3

Proof. $S_{A}$ takes the first derivative of $T_{1}$ and $T_{2}$. Thus, we can obtain 


$$
\begin{aligned}
& \frac{\partial S_{A}}{\partial T_{1}}=\frac{\alpha_{0} e_{1}-C_{1}}{2\left[T_{1}+\left(\alpha_{0}-\alpha_{1}\right) e_{1}-R_{1}\right]^{2}}>0, \\
& \frac{\partial S_{A}}{\partial T_{2}}=\frac{-\left(\beta_{0} e_{2}-C_{2}\right)}{2\left[T_{2}+\left(\beta_{0}-\beta_{1}\right) e_{2}-R_{2}\right]^{2}}<0 .
\end{aligned}
$$

Inference A.4

Proof. $S_{A}$ takes the first derivative of $C_{1}$ and $C_{2}$. Thus, we can obtain

$$
\begin{aligned}
& \frac{\partial S_{A}}{\partial C_{1}}=\frac{1}{2\left[T_{1}+\left(\alpha_{0}-\alpha_{1}\right) e_{1}-R_{1}\right]^{2}}>0, \\
& \frac{\partial S_{A}}{\partial C_{2}}=\frac{-1}{2\left[T_{2}+\left(\beta_{0}-\beta_{1}\right) e_{2}-R_{2}\right]^{2}}<0 .
\end{aligned}
$$

\section{Data Availability}

The data used to support the findings of this study have not been made available because raw data are hard to reach, and this paper uses hypothetical data for simulation rather than real data.

\section{Conflicts of Interest}

The authors declare no conflicts of interest.

\section{Acknowledgments}

This work was funded by the National Nature Science Foundation of China (grant no. 11501236) and the National Social Science Foundation of China (grant no. 18BRK003).

\section{References}

[1] J. Wang, T. Chen, and J. Wang, "Research on cooperation strategy of enterprises' quality and safety in food supply chain," Discrete Dynamics in Nature and Society, vol. 2015, Article ID 301245, 15 pages, 2015.

[2] H. F. Gale and J. C. Buzby, "Imports from China and food safety issues," Economic Information Bulletin No. 52, U.S. Department of Agriculture, Economic Research Service, Washington, DC, USA, July 2009.

[3] J.-S. Chen, "What can we learn from the 2008 melamine crisis in China?," Biomedical and Environmental Sciences, vol. 22, no. 2, pp. 109-111, 2009.

[4] F. Lu and X. Wu, "China food safety hits the "gutter"," Food Control, vol. 41, pp. 134-138, 2014.

[5] G. Qiao, T. Guo, and K. K. Klein, "Melamine and other food safety and health scares in China: comparing households with and without young children," Food Control, vol. 26, no. 2, pp. 378-386, 2012.

[6] J. E. Hobbs, "Information asymmetry and the role of traceability systems," Agribusiness, vol. 20, no. 4, pp. 397-415, 2004.

[7] O. Hart and J. Moore, "Foundations of incomplete contracts," Review of Economic Studies, vol. 66, no. 1, pp. 115-138, 1999.
[8] J. E. Stiglitz and A. Weiss, "Credit rationing in markets with imperfect information," American Economic Review, vol. 71, no. 3, pp. 393-410, 1981.

[9] G. Akerlof, The Market for "Lemons": Quality Uncertainty and the Market Mechanism, Macmillan Education UK, London, UK, 1995.

[10] J. M. Antle, "Efficient food safety regulation in the food manufacturing sector," American Journal of Agricultural Economics, vol. 78, no. 5, pp. 1242-1247, 1996.

[11] M. Cantley, "How should public policy respond to the challenges of modern biotechnology?," Current Opinion in Biotechnology, vol. 15, no. 3, pp. 258-263, 2004.

[12] B. Halkier and L. Holm, "Shifting responsibilities for food safety in Europe: an introduction," Appetite, vol. 47, no. 2, pp. 127-133, 2006.

[13] E. Vos, "EU food safety regulation in the aftermath of the BSE crisis," Journal of Consumer Policy, vol. 23, no. 3, pp. 227-255, 2000.

[14] R. K. Mueller, "Changes IN the wind IN corporate governance," Journal of Business Strategy, vol. 1, no. 4, pp. 8-14, 1981.

[15] Y. He, D. Li, S. J. Wu, C. Shi, and S. J. Wu, "Quality and operations management in food supply chain," Journal of Food Quality, vol. 2018, Article ID 7279491, 4 pages, 2018.

[16] G. Roels, U. S. Karmarkar, and S. Carr, "Contracting for collaborative services," Management Science, vol. 56, no. 5, pp. 849-863, 2010.

[17] O. Kaya, "Outsourcing vs. in-house production: a comparison of supply chain contracts with effort dependent demand," Omega, vol. 39, no. 2, pp. 168-178, 2011.

[18] Y.-C. Tsao and G.-J. Sheen, "Effects of promotion cost sharing policy with the sales learning curve on supply chain coordination," Computers \& Operations Research, vol. 39, no. 8, pp. 1872-1878, 2012.

[19] T. A. Taylor, "Supply chain coordination under channel rebates with sales effort effects," Management Science, vol. 48, no. 8, pp. 992-1007, 2002.

[20] Y. He, X. Zhao, L. Zhao, and J. He, "Coordinating a supply chain with effort and price dependent stochastic demand," Applied Mathematical Modelling, vol. 33, no. 6, pp. 27772790, 2009.

[21] D. W. Lachenmeier, S. Löbell-Behrends, W. Böse, G. Marx, W. Boese, and Gerhard, "Does European Union food policy privilege the internet market? Suggestions for a specialized regulatory framework," Food Control, vol. 30, no. 2, pp. 705-713, 2013.

[22] M. A. Al-Busaidi and D. J. Jukes, "Assessment of the food control systems in the Sultanate of Oman," Food Control, vol. 51, pp. 55-69, 2015.

[23] S. C. O. Wertheim-Heck, S. Vellema, and G. Spaargaren, "Food safety and urban food markets in Vietnam: the need for flexible and customized retail modernization policies," Food Policy, vol. 54, pp. 95-106, 2015.

[24] P. Liu, "Chinese food safety regulation: an empirical study on regime change and performance evaluation," Journal of Public Management, vol. 7, no. 2, pp. 63-78, 2010.

[25] Y. Ren, Y. F. An, and X. L. Duo, "Function conversion and strategy choice of government in food safety supervision: a case study in beijing market," Journal of Public Management, vol. 8, no. 1, pp. 16-25, 2011.

[26] Y. Cao, C. Y. Yu, and G. Y. Wan, "Food company regulation game research under government participation," Journal of Systems Engineering-Theory \& Practice, vol. 37, no. 1, pp. 140-150, 2017. 
[27] S. Zhang, "The scientific basis of food safety supervision and typical case analysis," Journal of Chinese Institute of Food Science Technology, vol. 13, no. 2, pp. 1-5, 2013.

[28] K. Sigmund and M. A. Nowak, "Evolutionary game theory," Current Biology, vol. 9, no. 14, pp. 503-505, 2001.

[29] J. M. Smith and G. R. Price, "The logic of animal conflict," Nature, vol. 246, no. 5427, pp. 15-18, 1973.

[30] B. Sikhar, A. Gaurav, W. J. Zhang, M. Biswajit, and M. K. Tiwari, "A decision framework for the analysis of green supply chain contracts: an evolutionary game approach," Expert Systems with Applications, vol. 39, no. 3, pp. 29652976, 2012.

[31] P. D. Taylor and L. B. Jonker, "Evolutionarily stable strategies and game dynamics," Mathematical Biosciences, vol. 40, no. 12, pp. 145-156, 1978.

[32] P. He, Y. He, and F. Xu, "Evolutionary analysis of sustainable tourism," Annals of Tourism Research, vol. 69, pp. 76-89, 2018.

[33] L. Gu, L. Xi, and S. Wen, "Exploration on the low-carbon strategy based on the evolutionary game between the government and highway logistics enterprises," Agro Food Industry Hi-Tech, vol. 28, no. 1, pp. 1796-1800, 2017.

[34] R. Fan, L. Dong, W. Yang, and J. Sun, "Study on the optimal supervision strategy of government low-carbon subsidy and the corresponding efficiency and stability in the small-world network context," Journal of Cleaner Production, vol. 168, pp. 536-550, 2017.

[35] L. Shen and Y. Wang, "Supervision mechanism for pollution behavior of Chinese enterprises based on haze governance," Journal of Cleaner Production, vol. 197, pp. 571-582, 2018.

[36] Y. Mai, "Iop, evolutionary game analysis of government regulation and enterprise emission from the perspective of environmental tax," in Proceedings of the 1st International Global on Renewable Energy and Development, vol. 100, Singapore, December 2017.

[37] F. Chen, H. Chen, D. Guo, S. Han, and R. Long, "How to achieve a cooperative mechanism of MSW source separation among individuals - an analysis based on evolutionary game theory," Journal of Cleaner Production, vol. 195, pp. 521-531, 2018.

[38] M.-H. Chen, L. Wang, S.-W. Sun, J. Wang, and C.-Y. Xia, "Evolution of cooperation in the spatial public goods game with adaptive reputation assortment," Physics Letters A, vol. 380, no. 1-2, pp. 40-47, 2016.

[39] Q. Shi, J. Zhu, and Q. Li, "Cooperative evolutionary game and applications in construction supplier tendency," Complexity, vol. 2018, Article ID 8401813, 13 pages, 2018.

[40] X. Ma, "Analysis on quality control in food supply chain based on dynamics evolutionary game model," in Proceedings of the International Conference on Intelligent Computation Technology and Automation, vol. 2010, pp. 698-701, Changsha, China, May 2010.

[41] M. L. Xu, Q. Wang, and L. H. Ouyang, "Investment decision of food supply chain quality based on the evolutionary game," Chinese Journal of Management Science, vol. 20, no. 5, pp. 131-141, 2012.

[42] Y. Cao, Z. Y. Yu, and G. Y. Wan, "Evolutionary game study between government and enterprises in food adulteration under the new media environment," Chinese Journal of Management Science, vol. 25, no. 6, pp. 179-187, 2017.

[43] X. Su, S. Duan, S. Guo, and H. Liu, "Evolutionary games in the agricultural product quality and safety information system: a multiagent simulation approach," Complexity, vol. 2018, pp. 1-13, 2018.

[44] D. Friedman, "Evolutionary games in economics," Econometrica, vol. 59, no. 3, pp. 637-333, 1991. 


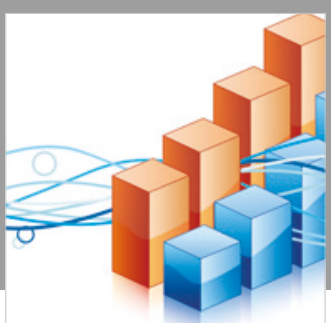

Advances in

Operations Research

\section{-n-m}
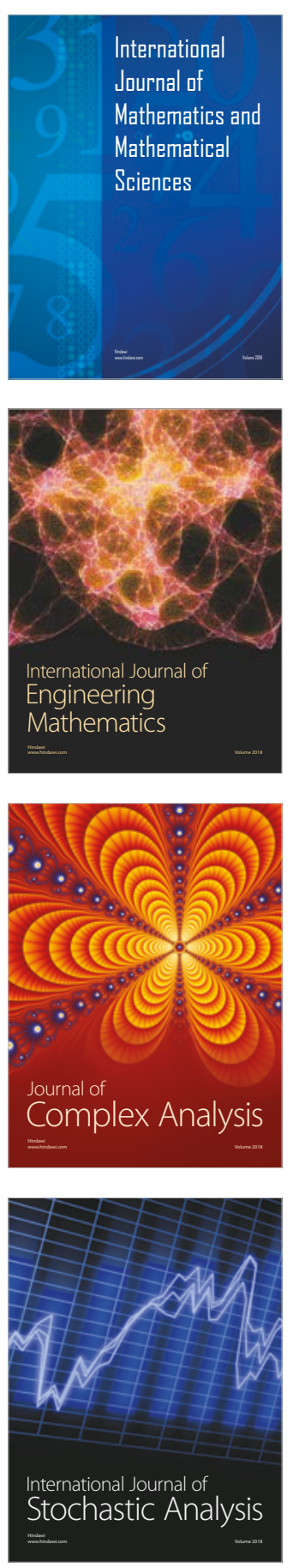
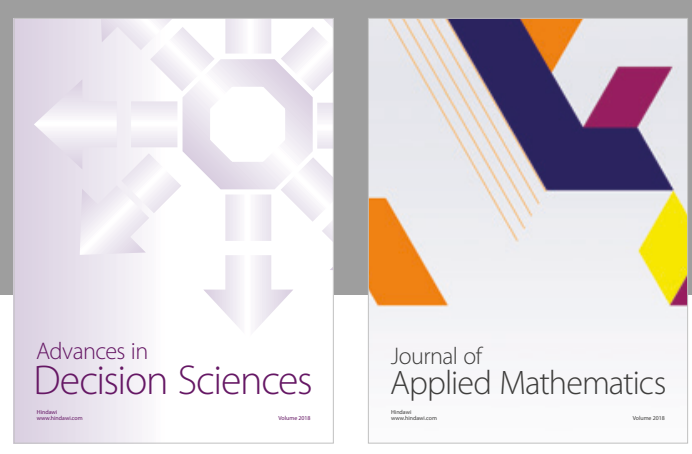

Journal of

Applied Mathematics
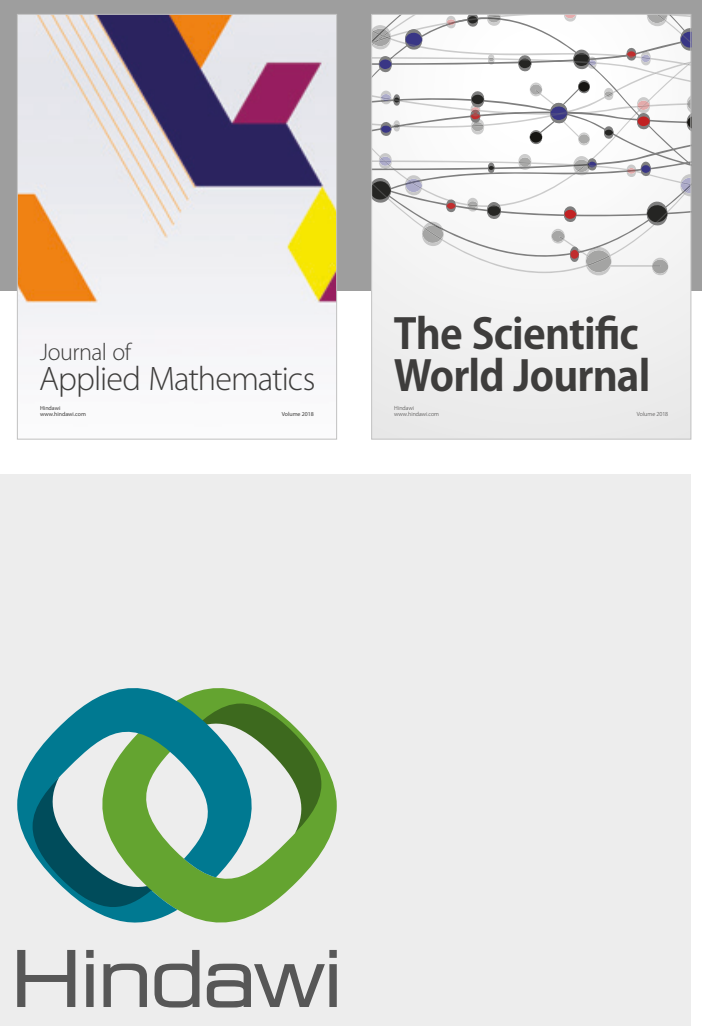

Submit your manuscripts at

www.hindawi.com

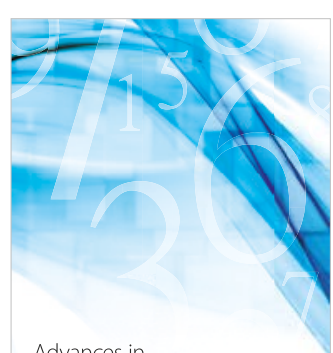

Advances in
Numerical Analysis
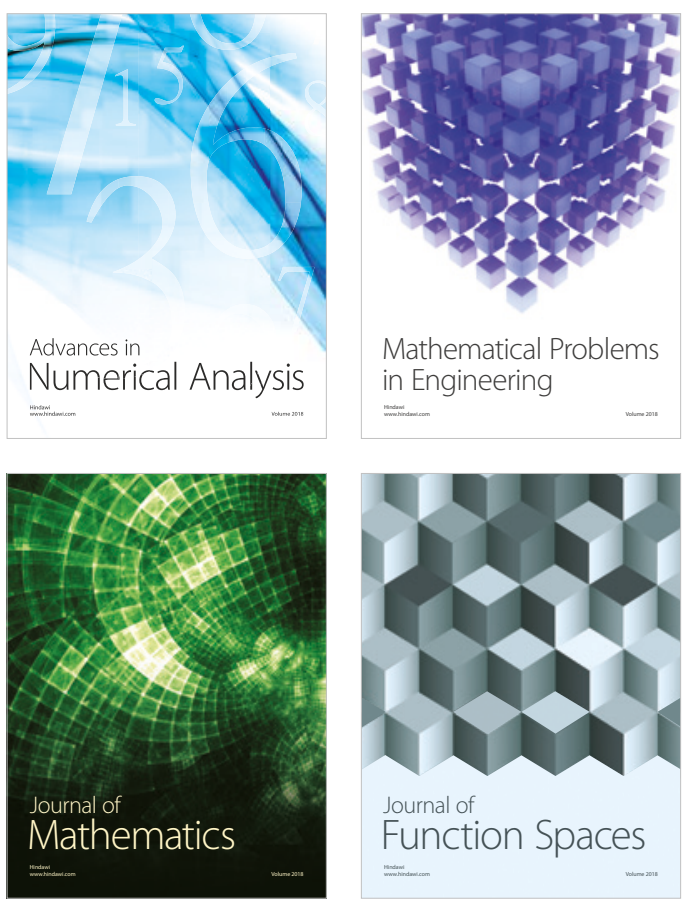

Mathematical Problems in Engineering

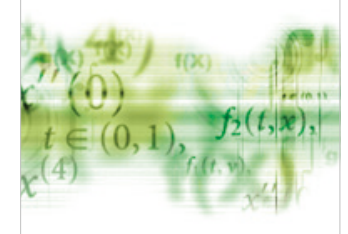

International Journal of

Differential Equations

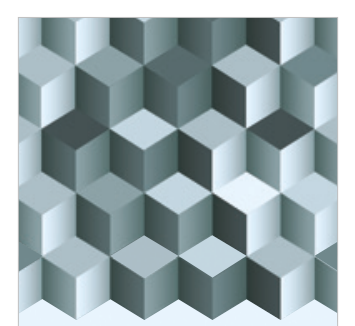

Journal of

Function Spaces
The Scientific

World Journal

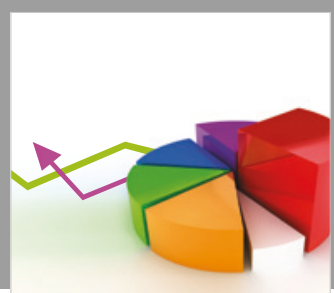

Journal of

Probability and Statistics
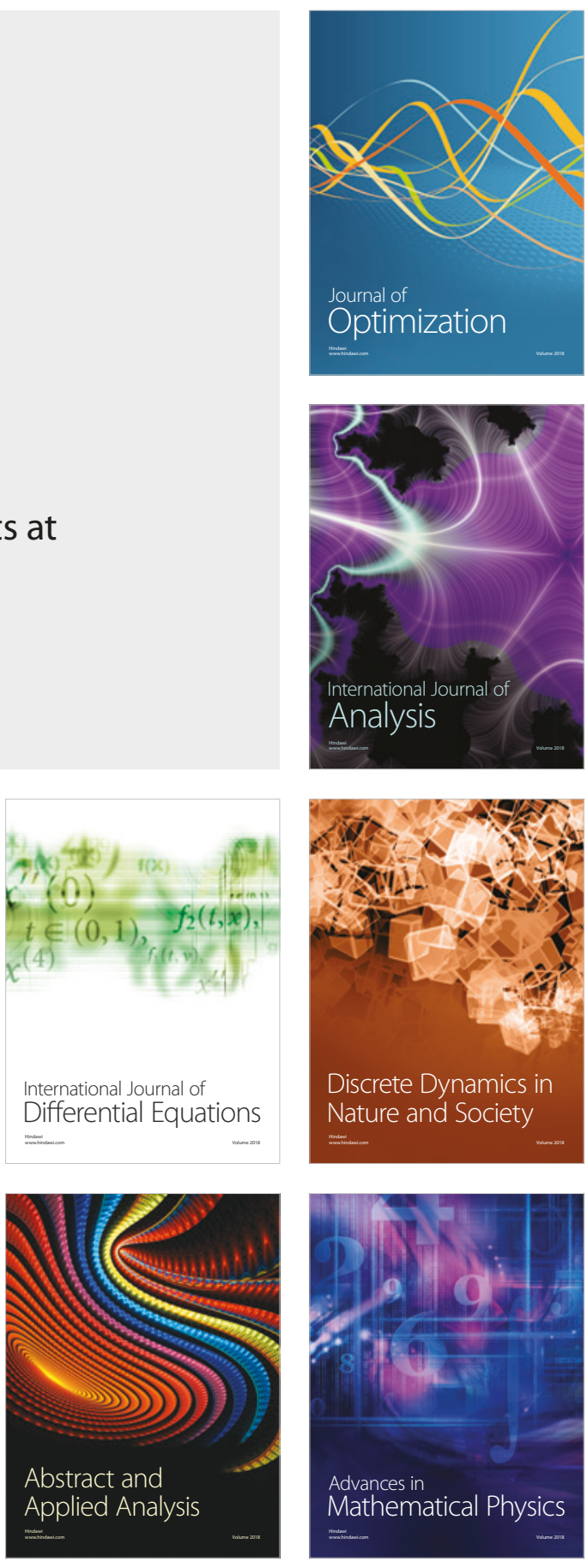